\title{
Maior dificuldade fitossanitária à produção da laranja no principal cinturão citrícola brasileiro - safras de 2017 a 2019
}

\author{
Gerônimo Guerreiro Neto ${ }^{1 *} \&$ Sérgio Rangel Fernandes Figueira ${ }^{1}$
}

\begin{abstract}
RESUMO
A produção da laranja é impactada por inúmeros fatores, variando conforme a região geográfica onde está localizada. O objetivo deste trabalho foi identificar junto aos produtores de laranja do principal cinturão citrícola brasileiro (São Paulo e o Triângulo/Sudoeste Mineiro) a principal dificuldade fitossanitária para a produção nas safras 2017, 2018 e 2019. Em 922 propriedades, estratificadas em número de plantas: até $20.000 ; 20.001$ a 100.000 e mais que 100.000 , divididas em 12 regiões e 5 setores, foram realizadas 260 entrevistas estruturadas, uma em cada propriedade. Com 93\% de nível de confiança e 5\% de erro amostral, foi identificado que: as principais dificuldades à produção em todos os setores juntos foi o fator fitossanitário e a adversidade climática, com 39\% e 36\% das respostas, respectivamente. Por setor, o aspecto fitossanitário foi a maior dificuldade à produção para o Centro, Sul e Sudoeste do cinturão citrícola, enquanto clima adverso foi a maior dificuldade para os setores Norte e Noroeste do cinturão citrícola. Quanto ao aspecto fitossanitário, o huanglongbing (HLB), ex-greening), foi a maior dificuldade para $70 \%$ dos produtores em todos os setores analisados em conjunto, com maior peso nos setores Centro, Sul e Sudoeste do cinturão citrícola. Causa fitossanitária (doenças e pragas) seria o principal motivo para o produtor deslocar sua produção para outra região. Pela pesquisa, os produtores identificam no HLB a principal dificuldade à produção da laranja no cinturão citrícola e, portanto, a principal ameaça à sua atividade.
\end{abstract}

Termos de indexação: HLB, setores produtivos, citros, entrevistas.

\section{Greater phytosanitary difficulty for orange production in the main Brazilian citrus belt - 2017-2019 harvests}

\section{SUMMARY}

Orange production is impacted by numerous factors, varying according to the geographic region where it is located. The objective of this work was to identify the main phytosanitary difficulty for the production in the 2017, 2018 and 2019 harvests with orange producers in the main Brazilian citrus belt (São Paulo and Triangle/Southwest Mineiro). In 922 properties, stratified by number of plants: up to 20,000; 20,001 to 100,000 and more than 100,000, divided into 12 regions and 5 sectors, 260 structured interviews were carried out, one in each property. With $93 \%$ of confidence level and $5 \%$ of sampling error, it was identified that: the main difficulties to production in all sectors

\footnotetext{
${ }^{1}$ Universidade Estadual Paulista - UNESP, Jaboticabal, SP, Brasil

*Autor correspondente: Gerônimo Guerreiro Neto. Universidade Estadual Paulista, UNESP, Rua Quintino Bocaiúva, 92, CEP:14700465, Bebedouro, SP, Brasil. E-mail: gneto1968@hotmail.com
} 
together were the phytosanitary factor and climate adversity, with $39 \%$ and $36 \%$ of the answers, respectively. By sector, the phytosanitary aspect was the greatest difficulty for production for the Center, South and Southwest of the citrus belt, while adverse weather was the greatest difficulty for the North and Northwest sectors of the citrus belt. As for the phytosanitary aspect, huanglongbing (HLB), ex-greening), was the greatest difficulty for $70 \%$ of producers in all sectors analyzed together, with greater weight in the Center, South and Southwest sectors of the citrus belt. Phytosanitary causes (diseases and pests) would be the main reason for the producer to move his production to another region. Through the research, the producers identify in the HLB the main difficulty for orange production in the citrus belt and, therefore, the main threat to their activity.

Index terms: HLB, productive sectors, citrus, interviews.

\section{INTRODUÇÃO}

O Brasil é o maior produtor mundial de laranja, com área destinada à colheita de 595,3 mil hectares em 2018 (IBGE, 2020), sendo responsável por 34\% da produção da fruta cítrica, $56 \%$ do suco produzido no mundo, com participação de $76 \%$ no comércio mundial de suco de laranja, sendo o maior exportador da bebida no planeta. O parque citrícola de São Paulo e Triângulo/ Sudoeste Mineiro - 'cinturão citrícola' - é a principal região produtora do país, presente em 350 municípios, gerando 200 mil empregos diretos e indiretos e movimentando US\$ 14 bilhões por ano (FUNDECITRUS, 2019). Somente com a cultura da laranja dentro do cinturão citrícola são 407,7 mil hectares (FUNDECITRUS, 2020).

A citricultura no Brasil tem uma longa história de desafios, já que nas últimas décadas, algumas das mais importantes doenças introduzidas no país tiveram impacto nessa cultura: vírus da tristeza dos citros- CTV (1937), cancro cítrico (1957), mancha preta do citros - MPC (1980), clorose variegada do citros - CVC ou amarelinho em 1987, a morte súbita do citrus (MSC) a partir de 2001, e o huanglongbing (HLB), ex-greening) em 2004 (Borges \& Costa, 2005; Bassanezi et al., 2017). Segundo Figueiredo (2008), estima-se que mais de 300 pragas e doenças estiveram, e muitas ainda estão presentes, nos pomares de citros paulista, tendo gerado perdas econômicas relevantes, inclusive oriundas da erradicação de número significativo de árvores.

A citricultura do estado de São Paulo tem sido acometida nas últimas décadas pelo surgimento e o avanço de importantes e limitantes doenças, MPC dos citros, leprose dos citros, MSC dos citros, CVC dos citros, o HLB, e o cancro cítrico, desencadeando aumento de custos relativos aos tratamentos fitossanitários, nos danos na produção e qualidade das frutas, reduzindo a vida útil das plantas e com aumento dos riscos a cultura (Bassanezi et al., 2012). Em 2004, surgem plantas com sintomas de HLB em
Araraquara (SP), (Coletta-Filho et al., 2004), causando a eliminação de 26,7 milhões de plantas entre os anos de 2005 e 2012, dentro do Cinturão Citrícola (FUNDECITRUS, 2013). A incidência média de laranjeiras com sintomas de HLB no cinturão citrícola de São Paulo e Triângulo/ Sudoeste de Minas Gerais, em 2021, é de 22,37\%, o que corresponde a aproximadamente 43,4 milhões de árvores (FUNDECITRUS, 2021). O psilídeo dos citros - Diaphorina citri Kuwayama (Hemiptera: Psyllidae), é importante praga dos citros, pois transmite bactérias do floema (Candidatus Liberibacter spp) com a Ca. L. asiaticus (LAS)] que estão associadas ao HLB, a mais importante doença dos citros do mundo (Hall et al., 2013; Erpen et al., 2018).

A incidência de doenças nos pomares de laranja é um problema bastante sério enfrentado pelos citricultores, onde o combate à doença provoca aumentos nos custos de produção, com a contratação de mão-de-obra especializada, uso de produtos químicos e com erradicações obrigatórias, sendo o HLB, a mais destrutiva das doenças atuais, (Yamamoto et al., 2015; Rossi, 2017). Segundo Silva \& Scare (2015), o HLB é a principal limitação fitossanitária aos citricultores que pretendem permanecerem na citricultura no Estado de São Paulo.

Pela limitação na produção, com queda na produtividade e aumento nos custos, problemas fitossanitários podem inviabilizar a cultura em uma determinada região. A Secretaria de Agricultura e Abastecimento do Estado de São Paulo (2009), aponta que por sérios problemas fitossanitários da citricultura, existe tendência de transposição de parte da área plantada da região tradicional (compreendida entre as regiões Norte e Centro-Sul do Estado de São Paulo) para diversos municípios do Sudoeste paulista, tais como: Buri, Itapetininga, Avaré, Angatuba e Paranapanema.

A citricultura que até então se concentrava ao Norte do cinturão citrícola (São Paulo e Triângulo/Sudoeste Mineiro), se deslocou para regiões com menos tradição, no Sudoeste paulista. Condições climáticas mais favoráveis, menor pressão de pragas e doenças e menor valor das 
terras tiveram influência nesta dinâmica (Neves et al., 2010). Nos últimos anos, as áreas de laranja situadas nas regiões tradicionais do Norte e Centro-Sul do Estado de São Paulo vêm apresentando redução. No entanto, a região Sudoeste caracteriza-se por maior incremento tanto na área plantada como na produção de frutos. O deslocamento da citricultura para esta região, além de possuir condições adequadas ao plantio, foi uma alternativa para minimizar o efeito das doenças que oneram o processo produtivo (Caputo, 2012). A citricultura é uma das cadeias do agronegócio com maior geração de renda e com maior índice de empregos por hectare, do estado de São Paulo e do Triângulo Mineiro, principalmente porque toda a colheita, que se estende por cerca de dez meses, é feita de forma manual (FUNDECTRUS, 2019). Estudos nessa área têm grande importância para a economia dessa região.

O objetivo geral da pesquisa foi identificar qual a principal dificuldade fitossanitária à produção da laranja enfrentada pelo produtor dentro do principal Cinturão Citrícola brasileiro, nas safras 2017, 2018 e 2019, e seus impactos. Para atingir o objetivo geral da pesquisa foram identificados os seguintes objetivos específicos: principais dificuldades na produção da laranja - geral e por setor; maiores dificuldades fitossanitários- geral e por setor; \% de plantas com HLB nos pomares por estrato produtivo, aumento nos custos de produção em função do HLB $e$ motivos para deslocar plantio de laranja da região onde está instalado para outra região. A pesquisa possui relevância acadêmica e de políticas públicas por ajudar a compreender às dificuldades e ameaças que colocam em risco a produção de laranja na principal região citrícola do Brasil. Existe ainda relevância gerencial e empresarial no sentido de antecipar a eventuais riscos de abastecimento de laranja às fábricas, elevando custos e gerando insegurança no fornecimento de matéria prima.

\section{MATERIAL E MÉTODO}

A pesquisa utilizou a aplicação de entrevistas estruturadas em propriedades citrícolas com laranja dentro do cinturão citrícola, dividido em 5 setores e 12 regiões: Triângulo Mineiro, Bebedouro, Altinópolis, Votuporanga, São José do Rio Preto, Duartina, Matão, Brotas, Porto- Ferreira, Limeira, Avaré e Itapetininga. As questões das entrevistas, todas fechadas, foram aplicadas pessoalmente ou por telefone com o produtor ou o gestor da propriedade, cada uma refletindo a realidade de uma propriedade com laranja. Todas as entrevistas foram aplicadas mediante o uso de um aparelho de "tablet" no formato digitalizado. As perguntas fazem referência a percepção dos produtores para os temas tratados na pesquisa para as safras de 2017, 2018 e 2019. Seguem perguntas realizadas durante as entrevistas:

1- Qual a maior dificuldade enfrentada na produção de laranja nas safras 2017, 2018 e 2019?

( ) Problemas fitossanitários: como ataque de pragas e doenças nos pomares

( ) Oscilações nos preços da laranja por excesso ou falta da fruta

( ) Falta de mão de obra na colheita e alta em seus custos

() Alta nos preços dos insumos (adubo, corretivos, defensivos, diesel, etc.)

( ) Fatores climáticos adversos com impactos na produção

( ) Outra (as)

2- Qual é o principal problema fitossanitário enfrentado nas safras 2017, 2018 e 2019 ?
( ) Cancro cítrico ( ) CVC ( ) Bicho Furão
( ) (HLB) ( ) Morte súbita do citros ( MSC)
( ) Leprose ( ) Mancha Preta do Citros-MPC- ( ) Outro (a)

3- Qual a porcentagem de plantas doentes (sintomáticas) com HLB nos seus pomares em 2017, 2018, e 2019.

( ) $0 \%$

( ) Até $2 \%$ de plantas doentes

( ) De 2,1\% até $5 \%$ de plantas doentes

( ) De $5,1 \%$ até $15 \%$ de plantas doentes

( ) Mais que $15 \%$ de plantas doentes

4- Qual foi o aumento percentual dos custos de produção depois da introdução do HLB em sua propriedade nas safras 2017, 2018 e 2019 ?

() Até $5 \%$ ( ) De 5,1 até $10 \%$ ( ) De 10,1 até $20 \%$ ( )
De 20 até $30 \%$

( ) Mais que $30 \%$

5- Qual fator considera o mais importante para deslocar sua produção para outras regiões?

( ) Preço da terra mais em conta 
( ) Menor pressão de doenças e pragas

( ) Busca por clima mais favorável na produção

( ) Menor pressão de outras culturas pelo uso da terra

\section{( ) Outro fator}

Cada profissional de campo da empresa, treinado, e de posse deste equipamento, fez a entrevista ao respondente em sua visita de rotina, ou em visita agendada na propriedade, como também por telefone. Ao término da aplicação da pesquisa, gerou-se um banco de dados em Excel, posteriormente tabulado e analisado. A população a ser estudada foi de propriedades com laranja presentes no Estado de São Paulo e no Triângulo/Sudoeste Mineiro cinturão citrícola, pertencentes a uma carteira de cadastro de uma empresa processadora de suco de laranja, em uma população total de 922 propriedades). O plano amostral utilizado foi o plano estratificado com distribuição proporcional das amostras selecionadas dentro dos estratos (Bussab \& Morettin, 2002). Esse plano amostral foi selecionado com intuito de se obter uma amostra mais representativa e abrangente da população em questão. Os estratos utilizados foram os tamanhos das propriedades medidos em relação ao número de plantas (pés de laranjas) contidos na propriedade, e região geográfica. A divisão das regiões estratificadas foi escolhida de acordo com as regiões geográficas definidas pelo Fundecitrus, que divide o cinturão citrícola em 5 Setores: Norte, Noroeste, Centro, Sul e Sudoeste) e 12 regionais. O setor Norte engloba as regiões do Triangulo Mineiro, Bebedouro e Altinópolis. O setor Noroeste engloba as regiões de Votuporanga e São José do Rio Preto. O setor Centro engloba as regiões de Duartina, Matão e Brotas. O setor Sul engloba as regiões de Porto Ferreira e Limeira. O setor Sudoeste engloba as regiões de Avaré e Itapetininga. As 12 regionais foram estratificadas igualmente ( 3 estratos) em quantidade de plantas (até 20.000 plantas; de 20.001 a 100.000 plantas, e mais que 100.000 plantas) para garantir uma melhor representatividade dos imóveis dentro do cinturão, bem como uma classificação por tamanho da propriedade. A distribuição proporcional das amostras respeitou a distribuição da população analisada (922 propriedades com laranja). Exemplo: Se o estrato X possui 5\% dos imóveis da população, então será alocado $5 \%$ das amostras para aquele estrato. A escolha dos imóveis selecionados dentro de cada estrato será feita de maneira aleatória, permitindo-se inferência sobre proporção de determinada característica observada nas respostas. Foi realizada a estimação de proporção populacional com população finita, com erro amostral de 5\% e nível de confiança de $95 \%$ segundo a Equação (1).

$$
\mathrm{n}=\frac{\mathrm{N}^{*} \hat{\mathrm{p}}^{*} \hat{\mathrm{q}}^{*}\left(Z_{\dot{a} / 2}\right)^{2}}{\hat{\mathrm{p}}^{*} \hat{\mathrm{q}}^{*}\left(Z_{\dot{\mathrm{a}} / 2}\right)^{2}+(\mathrm{N}-1)^{*} \mathrm{E}^{2}}
$$

Onde $N=922$ é o número total da população de fornecedores, $E=0,05$ é o erro amostral, $Z \alpha 2$ /é o valor crítico da distribuição normal correspondente ao grau de confiança desejado e p e q são as probabilidades de indivíduos pertencerem e não pertencerem a categoria. Como os valores de p e q não conhecidos adotaremos uma abordagem conservadora e substituiremos a expressão $\hat{p} * q^{\wedge}$ por 0,25 segundo (Bussab \& Morettin, 2002). Segundo a Equação (1) o número ideal de amostras para pesquisa seriam 272 questionários respondidos, porém por motivos de indisponibilidade ou recusa de alguns respondentes só foi possível realizar 260 questionários. Com essa diminuição, o nível de confiança desejado foi afetado e fixando o número de amostra realizado, o número da população e o erro amostral de $5 \%$ na Equação (1), obteve-se um nível de confiança de 93\%. Portanto, a pesquisa realizada com 260 questionários se manteve com 5\% de erro amostral, mas teve uma redução no nível de confiança de $95 \%$ para $93 \%$.

\section{RESULTADOS E DISCUSSÃO}

De 260 propriedades interrogadas através de seus proprietários ou gestores, a grande maioria (159) ou $61 \%$, são propriedades com laranja de pequeno porte, com até 20.000 plantas de laranja. 75 propriedades (29\%) são intermediárias, e somente $10 \%$ ou 26 são grandes, em conformidade com o inventário de plantas realizado pelo Fundecitrus em 2019, que aponta 77,6\% das propriedades do cinturão citrícola com até 20.000 plantas (Figura 1), em modelo de produção com pequenas propriedades, interessante no aspecto socioeconômico.

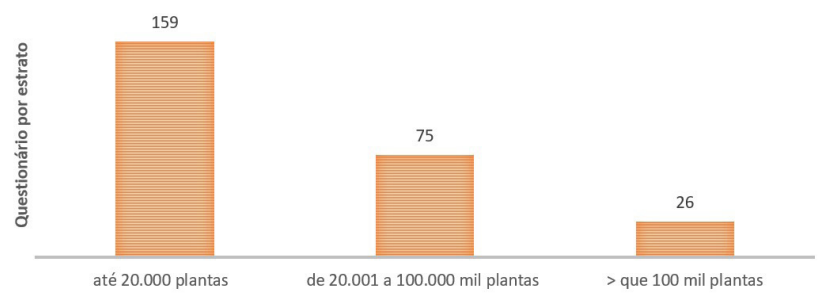

Figura 1. Questionários respondidos por estrato de número de plantas de laranja (Cinturão citrícola de São Paulo e Minas Gerais). 
A pesquisa identificou a percepção dos produtores com relação as dificuldades para produzir laranja nas últimas nas safras (2017, 2018 e 2019), em todos os setores (juntos) do cinturão citrícola. As respostas em percentual, para cada dificuldade estão na Figura 2. A questão fitossanitária, que envolve $o$ ataque de pragas e doenças nos pomares, foi o principal problema enfrentado pelos citricultores nas safras estudadas, com 39\% das respostas. A questão climática também foi bem pontuada, com 36\% das respostas. Questões econômicas importantes, à exemplo da oscilação no preço da laranja e aumento nos custos dos insumos, tiveram apenas $5 \%$ e $15 \%$ das respostas, respectivamente.

Pragas e doenças, sobretudo a CVC, MSC, o Cancro Cítrico e HLB, têm causado danos expressivos à citricultura brasileira, motivando enormes gastos com defensivos, tratos culturais e reimplantação de pomares. Considerando somente a última década as pragas e doenças foram responsáveis pela erradicação de 40 milhões de árvores (Neves et al., 2010; Erpen et al., 2018).

A pesquisa procurou identificar a percepção do produtor de laranja com relação as principais dificuldades nas safras 2017, 2018 e 2019, em cada setor separadamente. As respostas dos produtores estão consolidadas em $\%$ para cada setor produtivo e respectiva dificuldade (Tabela 1). A questão fitossanitária é considerada pelos setores Sudoeste, Sul e Centro como a maior dificuldade

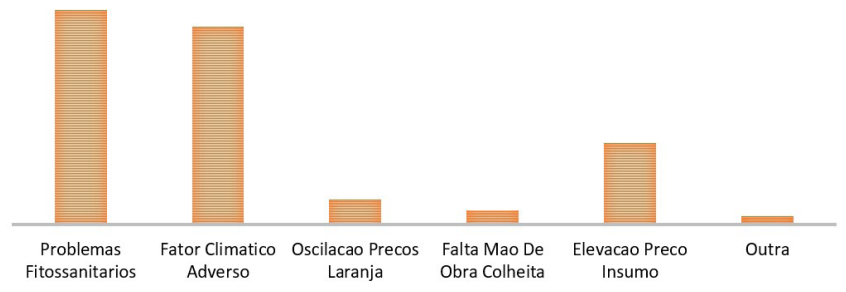

Figura 2. Dificuldade (\%) para se produzir laranja nas safras 2017,2018 e 2019, em todos os setores (Cinturão citrícola São Paulo e Minas Gerais). na produção - respectivamente $52 \%, 49 \%$ e $50 \%$ das respostas. Os aspectos fitossanitários, em especial as pragas e doenças, sempre foram um grande desafio para a citricultura brasileira, sendo que, a disseminação representa um risco relevante a produtividade dos pomares, exigindo investimentos em prevenção e controle, com impacto direto na rentabilidade do citricultor (Sanches et al., 2014; Bazzo, 2016).

Para os setores Norte e Noroeste, o fator climático foi a maior dificuldade na percepção dos citricultores com respectivamente $45 \%$ e $50 \%$ das respostas. Entre 2006 a 2016, existe uma evolução no número de dias com temperaturas superiores a $35^{\circ} \mathrm{C}$, sobretudo na região mais ao Norte do Estado de São Paulo, onde estão municípios importantes na produção como: Barretos, Bebedouro, Jales e Votuporanga (Crestana et al., 2017). Na safra 2020/21 dentro do Cinturão Citrícola a estiagem de longa duração e o calor intenso causaram prejuízos irreversíveis, como a morte de plantas espalhadas pelo talhão. Casos mais dramáticos foram vistos em alguns talhões de sequeiro, principalmente nos setores Norte, Noroeste e Centro, onde todas ou quase a totalidade das árvores do talhão morreram (FUNDECITRUS, 2020). A faixa de temperatura ideal para o bom desenvolvimento e produção das plantas cítricas está entre 25 a $30^{\circ} \mathrm{C}$ durante o dia, e entre 10 a $15^{\circ} \mathrm{C}$ no período da noite (Rodrigues, 1987). A laranjeira, e os outros citros, preferem climas com temperatura entre 23 e $32^{\circ} \mathrm{C}$ e umidade relativa do ar alta, sendo que acima de $40^{\circ} \mathrm{C}$ e abaixo de $13{ }^{\circ} \mathrm{C}$, a taxa de fotossíntese diminui, acarretando perdas de produtividade (Mattos Junior et al., 2005).

Altas temperaturas e o stress hídrico - que são questões relacionadas ao clima - vem prejudicando as produções das últimas safras no cinturão citrícola, seja pelo impacto negativo no florescimento como também na diminuição no peso dos frutos, sobretudo nos setores Norte e Noroeste, levando produtores destes espaços geográficos a fazerem uso de irrigação. Outra tática que também tem ganhado espaço no setor citrícola, é o produtor

Tabela 1. Dificuldade (\%) por setor na produção da laranja nas safras 2017, 2018 e 2019

\begin{tabular}{lccccc}
\hline \multicolumn{1}{c}{ Dificuldades/Setor } & Norte & Noroeste & Sudoeste & Sul & Centro \\
\hline Problemas fitossanitários & $32 \%$ & $28 \%$ & $52 \%$ & $49 \%$ & $50 \%$ \\
Fator climático adverso & $45 \%$ & $50 \%$ & $0 \%$ & $30 \%$ & $29 \%$ \\
Elevação preço insumo & $12 \%$ & $20 \%$ & $32 \%$ & $13 \%$ & $10 \%$ \\
Falta de mão obra colheita & $4 \%$ & $2 \%$ & $11 \%$ & $8 \%$ & $2 \%$ \\
Oscilações preços da laranja & $5 \%$ & $0 \%$ & $0 \%$ & $0 \%$ & $7 \%$ \\
Outra causa & $2 \%$ & $0 \%$ & $5 \%$ & $0 \%$ & $2 \%$ \\
Total & $100 \%$ & $100 \%$ & $100 \%$ & $100 \%$ & $100 \%$ \\
\hline
\end{tabular}


fazer uso da irrigação para estimular o florescimento nos meses de julho e agosto, em que a temperatura ainda é amena, evitando temperaturas elevadas. De setembro a novembro, ao Norte e Noroeste as temperaturas podem ultrapassar os $40^{\circ} \mathrm{C}$, impactando negativamente na florada e no pegamento dos frutos.

A questão climática não foi para os produtores do setor Sudoeste do cinturão citrícola, um fator de dificuldade na produção nas últimas safras, pois nenhum produtor deste setor citou o clima como problema. Em contrapartida, a alta nos preços dos insumos, encarecendo os custos de produção, foi pontuada por $32 \%$ destes citricultores (Sudoeste) como fonte de dificuldade. A questão da oscilação do preço do seu produto (laranja), na percepção do produtor, não foi para quase todos os setores, fonte de dificuldade em seu negócio. Somente o setor Norte e Centro possuem produtores que citaram este importante componente econômico como dificuldade na produção nas safras pesquisadas, contudo em baixos percentuais - respectivamente 5\% e 7\%. Dentro dos aspectos fitossanitários, a pesquisa captou qual foi o maior entrave à produção da laranja para o citricultor nas safras 2017, 2018 e 2019, nos setores juntos. Entre estes problemas, a doença do HLB foi o principal problema fitossanitário para $70 \%$ dos produtores questionados (Figura 3), em conformidade com os estudos desenvolvidos por Silva \& Scare (2015).

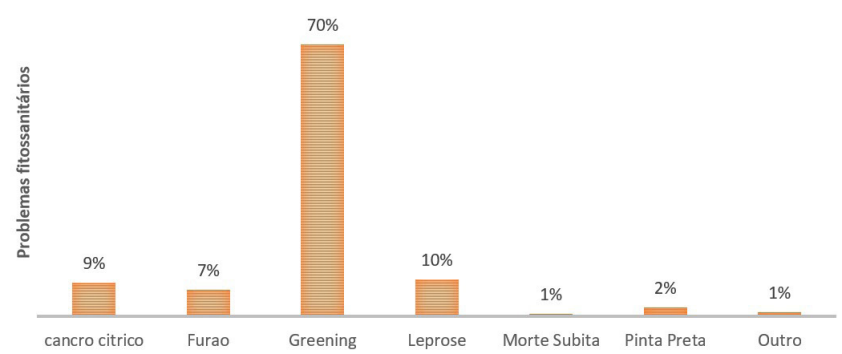

Figura 3. Principal problema fitossanitário nas safras 2017, 2018 e 2019 - setores juntos.
A pesquisa quando é analisada por setor produtivo, identifica -se que o HLB é o principal problema fitossanitário na percepção do produtor, independente do Setor. Contudo, algumas doenças como: leprose e cancro cítrico, e praga como o bicho furão, se apresentam como ameaças à produção nos setores Norte e Noroeste - na percepção dos citricultores (Tabela 2). A leprose está presente em praticamente todas as regiões produtoras de citros do país, especialmente no Estado de São Paulo, onde é mais severa nas regiões Norte e Noroeste, devido ao clima e aos períodos prolongados de estiagem que favorecem o aumento populacional do ácaro vetor (Bassanezi et al., 2002). Condições climáticas favoráveis ao ataque da leprose, e um número reduzido de acaricidas disponíveis no mercado para o controle do vetor (ácaro) da doença, dificultando o manejo e rotação de grupos químicos no campo, explicam as respostas dos produtores das regiões Norte e Noroeste para este problema fitossanitário.

O cancro cítrico foi apontado por boa parte dos citricultores dos setores Norte e Noroeste como um problema à produção de laranja. As regiões com as maiores incidências de cancro cítrico no cinturão citrícola atualmente, são: Votuporanga com 71,43\%, São José do Rio Preto com 39,32\%, Matão 29,31\% e Bebedouro com $24,18 \%$. As menores incidências estão nas regiões de Itapetininga com 0,38\%, Altinópolis $0,38 \%$ e Porto Ferreira com $0,66 \%$. A incidência de cancro cítrico é maior nas propriedades menores: em pomares com até 10 mil árvores, $22,42 \%$ das plantas apresentam sintomas (FUNDECITRUS, 2019). O HLB está espalhado por quase todo o cinturão citrícola, contudo as regiões nas extremidades do Cinturão Citrícola, a exemplo do Triângulo Mineiro, Votuporanga e Itapetininga, são possuidoras de menores incidências de HLB, ao contrário das regiões ao Central e Sul do Estado - severamente atacadas pela doença do HLB (FUNDECITRUS, 2018). A alta incidência do HLB nos pomares do setor Centro (Duartina, Matão e Brotas)

Tabela 2. Principal problema fitossanitário (\%) por setor nas safras 2017, 2018 e 2019

\begin{tabular}{lccccc}
\hline \multicolumn{1}{c}{ Fitossanidade/Setor } & Norte & Noroeste & Sudoeste & Sul & Centro \\
\hline Cancro cítrico & $8 \%$ & $28 \%$ & $0 \%$ & $0 \%$ & $0 \%$ \\
Bicho furão & $10 \%$ & $13 \%$ & $5 \%$ & $2 \%$ & $2 \%$ \\
HLB & $67 \%$ & $28 \%$ & $89 \%$ & $95 \%$ & $95 \%$ \\
Leprose & $11 \%$ & $26 \%$ & $0 \%$ & $0 \%$ & $0 \%$ \\
Morte súbita citrus & $1 \%$ & $2 \%$ & $0 \%$ & $0 \%$ & $0 \%$ \\
Mancha preta citrus & $2 \%$ & $2 \%$ & $0 \%$ & $3 \%$ & $3 \%$ \\
Outro & $1 \%$ & $1 \%$ & $6 \%$ & $0 \%$ & $0 \%$ \\
Total & $100 \%$ & $100 \%$ & $100 \%$ & $100 \%$ & $100 \%$ \\
\hline
\end{tabular}


e Sul (Limeira e Porto Ferreira), explica a dificuldade que o produtor destas regiões vem enfrentando em sua atividade e está em conformidade com os resultados da pesquisa. Ao serem questionados sobre o \% de HLB em seus pomares, $32 \%$ dos respondentes disseram ter até no máximo $2 \%$ de plantas com sintomas da doença. No entanto, $39 \%$ dos produtores questionados disseram ter mais de $5,1 \%$ de plantas com sintomas da pior doença que ataca a citricultura no momento (Figura 4).

Dados do Fundecitrus para 2019 indicam que o HLB está presente em 19,02\% das laranjeiras do cinturão citrícola de São Paulo e Triângulo/Sudoeste Mineiro, e que as regiões com maiores incidências de HLB são: Brotas (55,10\%), Limeira (48,30\%), Duartina (32,43\%), Porto Ferreira (26,67\%) e Matão (17,29\%). A incidência da doença cresceu em pomares menores: propriedades com até 10 mil plantas apresentam 47,49\% de árvores doentes e propriedades com 10,1 mil a $100 \mathrm{mil}, 31,10 \%$ de árvores sintomáticas. Nas propriedades de 100,1 mil a 200 mil plantas a incidência caiu e está em 16,17\%. A pesquisa captou junto aos entrevistados, o índice de HLB, por estrato de tamanho de produção em que o percentual de plantas sintomáticas é maior que 5,1\% (Figura 5). Propriedades maiores que 100.000 plantas apresentam menos plantas sintomáticas (para este nível da doença) que as de pequeno porte. Somente $27 \%$ das propriedades

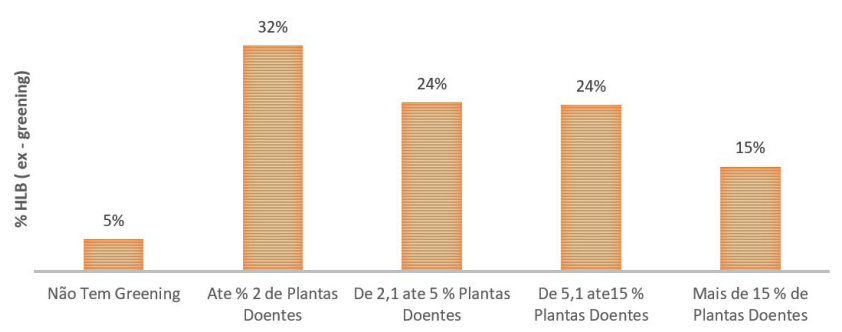

Figura 4. Porcentagem de plantas com HLB em 2019 na percepção dos produtores.

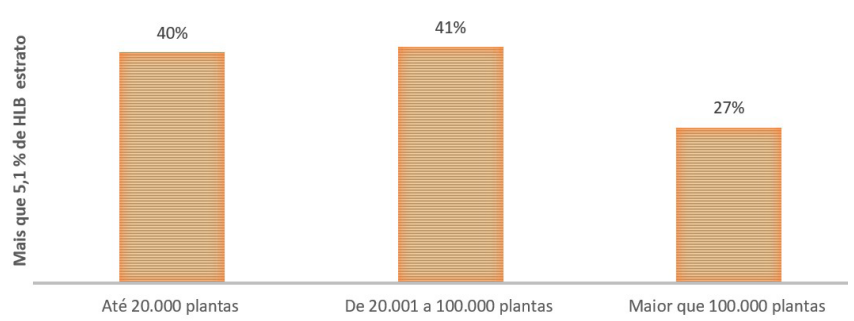

Figura 5. Porcentagem de plantas sintomáticas por HLB nos pomares com níveis maiores que $5,1 \%$ por estrato produtivo. (com mais de 100.000 plantas) que sofreram a entrevista, possuem mais que $5,1 \%$ de plantas com sintomas da doença, em detrimento as demais (pequenas e médias), que possuem no mínimo $40 \%$ de suas propriedades com HLB.

A maior parte das árvores contaminadas pelo HLB estão nos primeiros 200 metros dos pomares, que são as portas de entrada para o psilídeo (Diaphorinacitri), transmissor da bactéria que causa a doença (FUNDECITRUS, 2017). Este efeito "bordadura", que é uma maior área de exposição da propriedade ao vetor da doença, explica o porquê fazendas menores possuem mais HLB que as maiores. No avanço do HLB, no cinturão produtor (São Paulo e Triângulo Mineiro), as propriedades de menor porte são as mais afetadas, sendo que nas propriedades de até 10 mil plantas, o índice da doença está em 36,03\%. Já nas propriedades de 10,1 a 100 mil plantas e de 100,1 a 500 mil plantas os níveis da doença estão, respectivamente, em $29,15 \%$ e $14,88 \%$. As maiores propriedades, com mais de 500 mil plantas, são as menos atingidas, com 2,37\% de incidência. A proporcionalidade é explicada pelo chamado "efeito de borda" (FUNDECITRUS, 2018).

A percepção é que a doença do HLB se apresenta com maior agressividade quando a propriedade com laranja tem menor tamanho de produção. Produtores de menor tamanho tem maior dificuldade em administrar a doença do HLB, e isto tem impactos negativos em seu negócio. A produção agrícola em pequena escala é afetada por problemas fitossanitários que diminuem produtividade e elevam custos (Osório et al., 2017). Com a introdução do HLB nos pomares de laranja do Estado de São Paulo em 2004, houve uma mudança na rotina dos citricultores com relação ao controle fitossanitário. A doença do HLB, é a principal ameaça fitossanitária à citricultura atualmente. A presença da doença promove um aumento no número de pulverizações nos pomares para efeito do controle do psilídeo (vetor da doença), aumentando os custos de produção, com diminuição da rentabilidade dos citricultores (Bassanezi et al., 2012; Yamamoto et al., 2015; Alcantara, 2017; Rossi, 2017). Para 28\% dos produtores pesquisados, os acréscimos nos custos de produção ficaram entre 10,1 a $20 \%$ com o advento da doença. Para 9\% dos produtores o HLB elevou seus custos em mais de 30\%. (Figura 6). Sem exceção, todos os produtores questionados disseram ter acréscimos em seus custos com a introdução doença em seus pomares.

O controle do HLB pode representar mais de $20 \%$ dos gastos totais de um pomar de laranja no Estado de São Paulo (H. F. Brasil, 2019). O HLB ou Greening, 


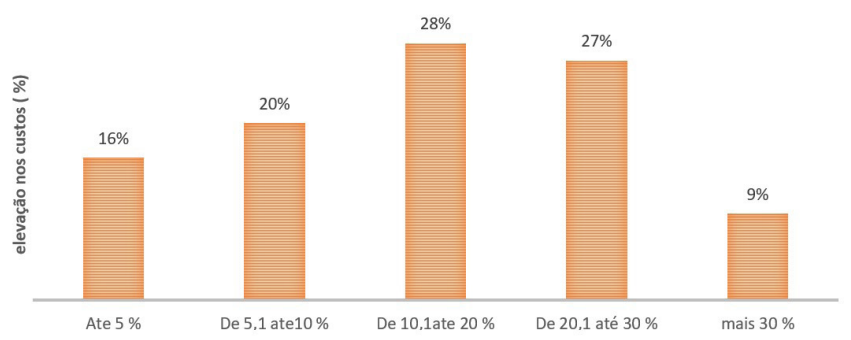

Figura 6. Elevação nos custos de produção pelo aparecimento do HLB nos pomares.

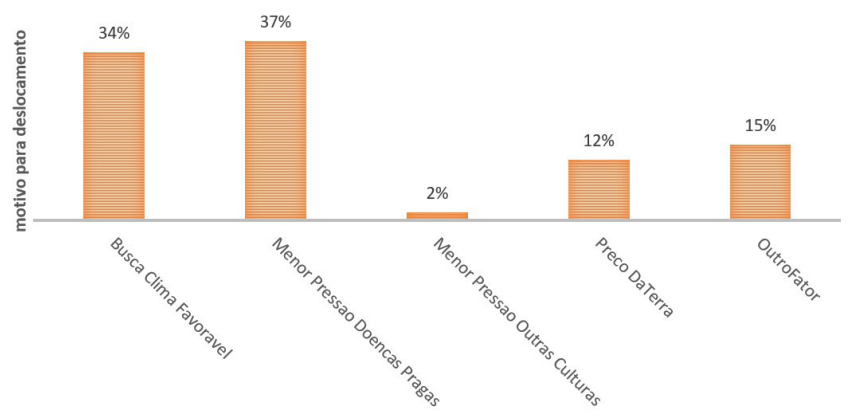

Figura 7. Motivo para o produtor deslocar (novos investimentos) sua produção para outra região.

contribui para o aumento no custo operacional da cultura, uma vez que o seu manejo envolve inspeções frequentes, erradicação de plantas sintomáticas, aplicações contínuas de inseticidas para o controle do vetor e replantio de mudas (Alcantara, 2017; Erpen et al., 2018). Nesse sentido, ciência e pesquisa, extensão rural, órgãos de governo e, sobretudo os produtores de citros, não podem "baixar a guarda" para esta importante doença. Outras doenças importantes surgidas na cultura da laranja prejudicaram colheitas e produções, contudo, os envolvidos da cadeia citrícola agiram em conjunto, de maneira a reerguer uma citricultura ainda mais forte e competitiva. Contudo o HLB é agressivo e desafiador, sobretudo com os pequenos citricultores, e isso pode desencadear enormes prejuízos econômicos e sociais, gerando desigualdades dentro da cadeia produtiva.

A pesquisa procurou identificar quais motivos levariam - independente se iria ou não - o produtor do Cinturão Citrícola à produzir laranja em outra região (diferente da que está atualmente). Captar o motivo do possível deslocamento reforça a identificação da maior dificuldade que o produtor vem enfrentando nas últimas safras. O principal motivo captado pela pesquisa seria a menor pressão de pragas e doenças (problemas fitossanitários) à produção em novas (outras) regiões, com $37 \%$ das respostas (Figura 7). Encontrar clima mais favorável à melhores colheitas em novos locais de produção, com $34 \%$ das respostas também seria um bom motivo para se deslocar para outras regiões. A presença de outras culturas que venham substituir a laranja na região em que o produtor está instalado, para ele, não é motivo para se deslocar, com somente 2\% das respostas positivas. Este baixo percentual não reflete o que vem acontecendo nos últimos anos, sobretudo na regional Centro e Norte do Estado de São Paulo (IBGE, 2018), onde principalmente a cana de açúcar vem substituindo áreas que até então tinham como cultura instalada e predominante a laranja, como apontado por Neves \& Lopes (2005) e Maçonaro (2017). Se deslocar para produzir laranja onde o preço da terra é mais baixo que o local à qual está instalado também não se configura em atrativo, com $12 \%$ de respostas positivas.

\section{CONCLUSÃO}

As maiores dificuldades enfrentadas pelos citricultores na produção da laranja dentro do cinturão citrícola nas safras 2017,2018, e 2019, são de ordem fitossanitária para os setores Centro, Sul e Sudeste, e climática para os produtores dos setores Norte e Noroeste. Com relação aos aspectos fitossanitários, em análise com todos os setores produtivos, $70 \%$ dos produtores consideram a doença do HLB o maior entrave à produção da laranja com maior peso para os Setores Sul, Centro e Sudoeste. Para o Setor Noroeste, o cancro cítrico é considerado problema sério a cultura da laranja, em equilíbrio ao HLB. 95\% das propriedades pesquisadas apresentam pelo menos 1 planta com HLB - portanto presença da doença. Propriedades grandes tem níveis de HLB inferiores em relação às pequenas e de médio porte. A doença do HLB é o "alvo" a ser batido pelos citricultores, como esclareceu a pesquisa, especialmente nos Setores Sul, Centro e Sudoeste do Cinturão (onde as condições climáticas são mais favoráveis à doença).

\section{REFERÊNCIAS}

Alcantara, M. R. (2017). A competitividade na produção de laranja: uma análise comparativa de custos no Brasil e Estados Unidos com ênfase na gestão e controle do Huanglongbing (HLB/Greening) (Tese de doutorado 
em). Faculdade de Engenharia Agrícola, Universidade Estadual de Campinas, Campinas.

Bassanezi, R. B., Belasque Júnior, J., Hamada, E., \& Ghini, R. (2012). Efeito das mudanças climáticas sobre doenças dos citros: estudo de caso do cancro cítrico. In Anais XXXV Congresso Paulista de Fitopatologia. Jaguariúna: Embrapa Meio Ambiente.

Bassanezi, R. B., Espósito, M. B., \& Yamamoto, P. T. (2002). Adeus à Leprose. Cultiva, 2(1), 6-8.

Bassanezi, R. B., Miranda, M. P., Lopes, S. A., Behlau, F., Silva Júnior, G. J., \& Sala, I. (2017). Influência de pragas e doenças na qualidade do suco de laranja. Recuperado em 17 setetembro de 2018, de https://www.fundecitrus. com.br/comunicacao/noticias/integra/artigo-influenciade-pragas-e-doencas-na-qualidade-do-suco-de-laranja/546

Bazzo, A. M. (2016) Distribuição intraplanta do ácaro da Leprose dos citros e adequação do volume de calda de acaricida para o seu controle (Dissertação de mestrado). Fundo de Defesa da Citricultura - FUNDECITRUS, Araraquara.

Borges, A. C. G., \& Costa, V. M. H. M. (2005). A evolução do agronegócio citrícola paulista e o perfil da intervenção do Estado. Revista Brasileira Multidisciplinar, 9(2), 101124. https://doi.org/10.25061/25272675/ReBraM/2006. v9i2.270

Bussab, W., \& Morettin, P. A. (2002). Estatística básica. São Paulo: Saraiva.

Caputo, M. M. (2012). Estudo avalia cultivares de laranja de maturação precoce. Recuperado em 3 de julho de 2018, de http://www.usp.br/agen/?p=107981.

Coletta-Filho, H. D., Targon, M. L. N., Takita, M. A., Negri, J. D., \& Pompeu JR, J. (2004). First report of the causal agent of Huanglongbing ("Candidatus Liberibacter asiaticus") in Brazil. Plant Disease, 88(12), 1382-1382.

Crestana, S., Foschini, M. M., \& Ferreia, M. D. (2017). Desafios da produção de frutas e hortaliças frente aos extremos climáticos - estudo de caso da citricultura paulista. In Ferreira, M. D. (Eds.), Instrumentação póscolheita em frutas e hortaliças (pp. 107-123). São Carlos: Embrapa Instrumentação.

Erpen, L., Muniz, F. R., Souza M. T., \& Rocha T E. C. (2018). Análise do cultivo da laranja no Estado de São Paulo de 2001 a 2015. Revista IPecege, 4(1), 33-43. Recuperado em 10 de maio de 2018, de https://doi. org/10.22167/r.ipecege.2018.1.33.
Figueiredo, M. G. (2008). Retorno econômico dos investimentos em pesquisa e desenvolvimento ( $P \& D)$ na citricultura paulista. (Tese de Doutorado). Escola Superior de Agricultura Luiz de Queiroz, Universidade de São Paulo, Piracicaba.

Fundo de Defesa da Citricultura - FUNDECITRUS. (2013). Greening é responsável pela eliminação de 26,7 milhões de plantas em oito anos. Recuperado em 22 de fevevereiro de 2018, de http://www.fundecitrus.com.br/ comunicacao/noticias/integra/Greening -e-responsavel-pelaeliminacao-de-267-milhoes-de-plantas-em-oito-anos/199.

Fundo de Defesa da Citricultura - FUNDECITRUS. (2017). Mesmo estabilizada, incidência de greening permanece alta no cinturão citrícola de São Paulo e Triângulo/ Sudoeste Mineiro. Recuperado em 05 de maio de 2018, de http://www.fundecitrus.com.br/comunicacao/noticias/ integra/mesmo-estabilizada-incidencia-de-Greeningpermanece-alta-no-cinturao-citricola-de-sao-paulo-etrianguloSudoeste-mineiro/559.

Fundo de Defesa da Citricultura - FUNDECITRUS. (2018). Inventário de árvores e estimativa da safra de laranja no cinturão citrícola de São Paulo e Triângulo/ Sudoeste Mineiro. Recuperado em 05 de novembro de 2018, de https://www.fundecitrus.com.br/pdf/pes relatorios/2018_05_21_Invent\%C3\%A1rio_e_Estimativa_ do_Cinturao_Citricola_2018-20191.pdf.

Fundo de Defesa da Citricultura - FUNDECITRUS. (2019). Quinze anos de greening no Brasil: como a citricultura de SP e MG tem conseguido controlar a doença e se manter como principal produtora de suco de laranja do mundo. Recuperado em 17 de janeiro de 2021, de https:// www.fundecitrus.com.br/comunicacao/noticias/integra/ quinze-anos-de-greening no-brasil-como-a-citriculturade-sp-e-mg-tem-conseguido-controlar-a-doenca-e-semanter-como-principal-produtora-de-suco-de-laranjado-mundo/777.

Fundo de Defesa da Citricultura - FUNDECITRUS. (2020). Inventário de árvores e estimativa da safra de laranja no cinturão citrícola de São Paulo e Triângulo/ Sudoeste Mineiro. Recuperado em 15 de dezembro de 2020, de https://www.fundecitrus.com.br/pdf/pes_ relatorios/2020_06_25_Invent\%C3\%A1rio_e_Estimativa_ do_Cinturao_Citricola_2020-20211.pdf.

Fundo de Defesa da Citricultura - FUNDECITRUS. (2021). Greening cresce pelo quarto ano consecutivo e alerta para necessidade de endurecimento das ações de controle. Recuperado em 29 de novembro de 2021, de 
https:/www.fundecitrus.com.br/comunicacao/noticias/ integra/greening-cresce-pelo-quarto-ano-consecutivoe-alerta-para-necessidade-de-endurecimento-das-acoesde-controle/1083.

Hall, D. G., Richardison, M. L., \& Ammar, E. D. (2013). Asian citrus psyllid, Diaphorina citri, vector of citrus Huanglongbing disease. Entomologia Experimentalis et Applicata, 146(2), 207-223, Recuperado em 20 de outubro de 2019, de https://onlinelibrary.wiley.com/doi/ full/10.1111/eea.12025.

Instituto Brasileiro de Geografia e Estatística - IBGE. (2020). Sistema IBGE de recuperação automática Sidra 2018: produção agrícola municipal. Recuperado em 23 de setembro de 2020, de https://sidra.ibge.gov.br/ pesquisa/pam/tabelas.

Instituto Brasileiro de Geografia e Estatística - IBGE. (2020). Sistema IBGE de recuperação automática Sidra 2018: produção agrícola municipal. Recuperado em 23 de setembro de 2020, de https://sidra.ibge.gov.br/ pesquisa/ pam/tabelas.

MAÇORANO, R. P. Impacto das mudanças climáticas na dinâmica na citricultura no Estado de São Paulo. 2017. 88 f. Dissertação (Mestrado em Engenharia Agrícola) Faculdade de Engenharia Agrícola, Universidade Estadual de Campinas, Campinas, 2017.

Mattos Junior, D., Negri, J. D., Figueiredo, J. O., \& Pompeu Junior, J. (2005). Citros: principais informações e recomendações de cultivo. Recuperado em 06 de outubro de 2018, de http://www.iac.sp.gov.br/imagem informacoestecnologicas/43.pdf.

Neves, M. F., \& Lopes, F. F. (2005). Estratégia para a laranja no Brasil (223 pp). São Paulo: Atlas.

Neves, M. F., Trombin, V. G., Milam, P., Lopes, F. F., Cressoni, F., \& Kalaki, R. (2010). O retrato da citricultura brasileira (1. ed., 137 pp.). São Paulo: Citrus Br.

Osório, R. M. L., Lima, S. M. V., Sant'anna, R. L. S., \& Castro, A. M. G. (2017). Demandas tecnológicas da cadeia produtiva de laranja no Brasil. Latin American Journal of Business Management, 8(2), 40-66.

Revista Hortifruti Brasil - H. F. Brasil. (2019). Preços médios dos Hortifruticolas. Recuperado em 21 de setembro de 2019, de https://www.hfbrasil.org.br/br/banco-dedados-precos-medios-dos-hortifruticolas.aspx.

Rodrigues, O. (1987). Ecofisiologia dos citros. In P. R. C. Castro, S. O. Ferreira, \& T. Yamada (Eds.), Ecofisiologia da produção agrícola (pp. 149-162). Piracicaba: POTAFOS.

Rossi, F. R. (2017). Determinantes da adoção de irrigação por citricultores da região centro Norte do Estado de São Paulo (Tese de Doutorado). Universidade Federal de São Carlos, São Carlos.

Sanches, A. L., Miranda, S. H. G., Belasque, J. R. J., \& Bassanezi, R. B. (2014). Análise econômica da prevenção e controle do cancro cítrico no Estado de São Paulo. Revista de Economia e Sociologia Rural, 52(3), 549-566.

Secretaria de Agricultura e Abastecimento do Estado de São Paulo. (2009). Encontro de citricultura movimenta o Sudoeste Paulista. Recuperado em 2 de julho de 2018, de http:/www.agricultura.sp.gov.br/noticias/ encontro-de-citricultura-movimenta-o-Sudoeste-paulista/.

Silva, M. G. L., \& Scare, R. F. (2015). Comportamento de compra de defensivos agrícolas do citricultor paulista: as fontes de informação. Revista de Administração da UNIFATEA, 10(10), 65-79.

Yamamoto, P. T., Alves, G. R., \& Beloti, V. H. (2015). Manejo e controle do huanglongbing (HLB) dos cítricos. Investigación Agraria, 16(2), 69-82.

Recebido: Fevereiro 16, 2021

Aceito: Outubro 25, 2021

Como citar: Guerreiro Neto, G., \& Figueira, S. R. F. (2021). Maior dificuldade fitossanitária à produção da laranja no principal cinturão citrícola brasileiro - safras de 2017 a 2019. Citrus Research \& Technology, 42, e1066. https:// doi.org/10.4322/crt.22521. 